\title{
Off-premise alcohol purchasing in Australia: Variations by age group, income level and annual amount purchased
}

HENG JIANG $^{1}$,, SARAH CALLINAN $^{1}$, MICHAEL LIVINGSTON $^{1} \&$ ROBIN ROOM $^{1,2}$

${ }^{1}$ Centre for Alcohol Policy Research, School of Psychology and Public Health, La Trobe University, Melbourne, Victoria, Australia.

${ }^{2}$ Centre for Social Research on Alcohol and Drugs, Stockholm University, Stockholm, Sweden.

$=$

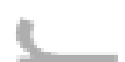

Short running title: Alcohol purchasing from off-premises

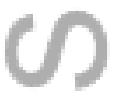

*Correspondence to Dr Heng Jiang, Centre for Alcohol Policy Research, School of Psychology and Public Health, La Trobe University, 215 Franklin Street, Melbourne, Vi 3000, Australia.

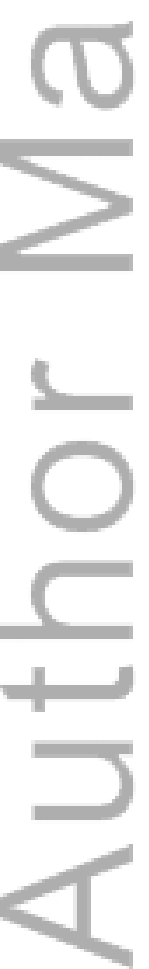

Email: jason.jiang@latrobe.edu.au; $\quad$ P: +61 394798795 .

This is the author manuscript accepted for publication and has undergone full peer review but has not been through the copyediting, typesetting, pagination and proofreading process, which may lead to differences between this version and the Version of Record. Please cite this article as doi: $10.1111 /$ dar.12402

This article is protected by copyright. All rights reserved. 


\section{Abstract}

Introduction and Aims: To delineate what type and how much alcohol is purchased from different types of off-licence premises and how this varies across demographic sub-groups, as a basis for public debate and decisions on pricing and planning policies to reduce alcohol-related harm in Australia.

Design and Methods: The data on alcohol purchasing from off-licence premises are taken from the Australian Alcohol Consumption and Purchasing survey -- a nationally representative landline and mobile telephone survey in 2013 on the experiences with alcohol consumption and purchasing of 2020 Australians aged 16+. The present analysis uses data from 1730 respondents who purchased alcohol from off-licence premises in the previous 6 months.

Results: The majority (54\%) of alcohol purchased from off-licence premises was sold from liquor barns (large warehouse-style alcohol stores), with bottle shops (31\%) the second most common outlet. Cask wine was the cheapest alcohol available at off-licence premises in Australia. Respondents in higher alcohol purchasing quintiles and with those with lower income purchased a higher percentage of cheaper alcohol in their total volume of purchasing than lower purchasing quintiles and those with middle and higher income, and younger respondents purchased more expensive alcohol than older age groups.

Discussion and Conclusions: A minimum unit price or increasing alcohol taxes may effectively reduce alcohol purchasing for lower income heavy alcohol purchasers and older age groups from offlicence premise sources, and may be less effective on younger age groups.

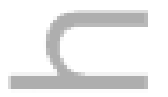

Key words: Alcohol, purchasing behaviour, off-premise, price, alcohol policy 


\section{Introduction}

Alcohol use and misuse is an important public policy issue because of its associations with acute injuries and chronic diseases, such as assaults, alcohol-related falls and drownings, drink driving injuries, liver cirrhosis, cancer and mental diseases [1]. Policies that control alcohol availability and increase retail prices are regarded internationally as effective options for limiting alcohol consumption and related harms [2].

=

In Australia, there has been a decline in drinking in on-licence premises and a growth in consumption of packaged alcohol beverages since the 1970s [3]. In part this has reflected cultural changes, such as an increase in drinking in the home as it became respectable for middle-class women [4], and technological innovations; for instance, since the 1970s, alcohol products were redesigned to make it easier for customers consume take-away alcohol, with packaging such as ring-pull cans, rip-top stubbies and wine casks [5]. The increasing price differences between on-licence and off-licence premises alcohol have also contributed to changing contexts of drinking [6].

A half-century ago, the primary off-licence premise sales location was the bottle-sales window in the local hotel (as Australian on-premise drinking places were traditionally called) [7]. Free-standing "bottle shops" were gradually introduced and the numbers steadily increased. Following changes to legislation in most jurisdictions in the 1980s and 1990s, grocery stores and some convenience stores can now obtain alcohol sales licenses in many parts of Australia [8]. More recently there has been the addition of what are called "liquor barns": large warehouse-style stores selling only alcohol, often in bulk. From the late 1990s on, Australia's two large "supermarket" chains, Coles and Woolworths, entered the alcohol retailing market, buying out liquor-barn chains and opening new outlets [9], so that by 2014 they together accounted for $59 \%$ of the total off-trade alcohol market [10]. 
Previous studies have found that higher levels of drinking in an area were associated with a higher density of off-premise outlets $[11,12]$. A recent report shows that the number of off-licence premise outlets and the total volume of alcohol sales from off-licence premises within a region are important predictors of assault [13]. Strong correlations have also been found between the growth of off-licence premise outlets and increases in alcohol-related harms, such as assaults, traffic crashes and domestic violence [14-16]. Researchers have hypothesised that these associations are related to the pressures on pricing stemming from the increasingly competitive packaged liquor market [15]. While much of this research has treated different types of packaged liquor outlets as a single category, there may be substantial differences between the impacts of large packaged outlets (e.g. liquor barns) and smaller outlets (e.g. convenience stores and small grocery stores) [17].

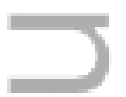

There is a substantial body of research demonstrating that alcohol prices are negatively correlated with alcohol purchasing and consumption [18-20]. For example, Canadian studies have shown that raising the minimum prices per standard drink reduces a population's level of consumption [21, 22]. With the recent policy debates about setting a minimum price for alcohol as a public health prevention strategy [23], several studies have modelled whose drinking would be affected how much by such a strategy. Using the British annual Expenditure and Food Survey, Meier et al. [24] found that the price elasticity of alcoholic beverages varies across different subpopulation groups, and estimated that setting a minimum unit price at 30 pence per UK standard unit of alcohol could effectively reduce alcohol consumption by harmful drinkers while having smaller effects on moderate drinkers. Two recent studies in Australia also projected varied effects of setting a minimum unit price or an increase in alcohol tax on alcohol consumption for high, moderate and low alcohol consumers [25, 26]. Previous studies also found that lower socioeconomic groups were more likely to purchase low price alcohol from off-licence premises and reported experiencing more alcohol-related harms for a given level of drinking than higher socioeconomic groups [27, 28]. Alcohol price policy has also been 
considered as a potential tool to reduce youth binge drinking [29, 30]. However, more research evidence is needed to understand how young people respond to alcohol price change.

Although there is increasing evidence that packaged liquor is a key contributor to alcohol-related harm [31], what differences there are in alcohol purchasing behaviours among different age groups, purchasing quintiles, income groups and other sub-populations have not been studied in Australia. While one recent study in Victoria found that outlets owned by the major chains sold cheaper alcohol than independent outlets, it didn't examine the differences between large packaged outlets and smaller outlets and lacked a national perspective [32]. Moreover, how beverage-specific prices differ between different types of off-licence premise outlets and how the differences affect consumer's purchasing, remain unclear, while no previous Australasian price policy studies have used national representative survey data. Using data collected in the 2013 Australian Alcohol Consumption and Purchasing study (ACAP), this paper assesses magnitudes and distributions of amounts and prices of alcohol beverages purchased by different demographic sub-groups and from different types of off-licence premises. Setting a minimum unit price for alcohol beverages at $\mathrm{A} \$ 1$ has been suggested as a standard in Australian discussions $[25,33]$. Thus $\$ 1$ per standard drink was used as the cut-off point to assess the proportion of volumes of low-cost alcohol purchased among different purchasing quintiles, age and income groups in this study. Our study further examines how alcohol purchasing among different subpopulation groups could be affected by introducing a minimum unit price at $\$ 1$ per Australian standard drink (ASD, one ASD = 10 grams ethanol and the Australian legal minimum drinking age is $18)$.<smiles>[CH][SiH2]</smiles><smiles>c1ccccc1</smiles>

\section{Data and Methods}

Data collection 
Data collection on the ACAP survey was undertaken between April and May 2013 (See the Appendix for the brief details of ACAP survey). Using appropriate probabilistic sampling methods, respondents were interviewed using computer-assisted telephone interviewing technology. The survey interviewed 2020 people aged 16 and above across Australia who spoke English [34]. Given the increasingly high proportions of Australians who do not have access to a landline telephone [36], the study was split into two subsamples: 1220 interviews using the standard random digit dialling approach on landlines, and a further 800 using a mobile phone-based random digit dialling sample. The sampling and weighting processes are elaborated in the Appendix. The response rate obtained for the general population survey was $37.2 \%$. After weighting (reflecting among other dimensions the oversampling of heavier drinkers), the sample was generally representative of the general Australian adult population.

Respondents were asked detailed questions on what they drink and where they drink it. The participants were further asked questions about what types of alcohol they purchased from off-licence premises and where they purchased it. In this study, we focus on analyses of alcohol purchasing from off-licence premise only. The participants were asked a series of questions to assess their alcohol purchasing behaviour in the last 6 months (see Appendix).

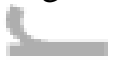

The purchasing questions measure places of alcohol purchasing, products and amount of alcohol purchased, and amounts of money spent on alcohol in the Australian population. Respondents provided the amount of alcohol they purchased in their own units (e.g. a bottle of wine or a pack of 6 regular beer cans) and how much they paid for it, then volumes of pure alcohol and price per standard drink were estimated by the research team based on average alcohol content and container sizes. The data were cleaned to deal with obvious outliers (e.g. a respondent who reported spending $\$ 20$ at an 
off-licence premise who said that he bought six 6-packs of regular beer cans would be coded as spending $\$ 20$ for a 6-pack of regular beer).

The amount of alcohol purchased by each respondent in the past 6 months was converted to Australian stândard drinks. This volume was doubled in the analysis to give an annual amount, to be comparable to other Australian survey analyses. Information on the amount and cost of alcohol purchased allowed a cost per standard drink to be calculated by beverage type and by outlet type. It should be recognised that the alcohol purchaser is not necessarily the person who will consume the alcohol. Purchases may be for others in the household or for provision for a specific social occasion, and gender roles within a particular family may play a part in who purchases the off-licence premise alcohol [37]. In the survey, 290 respondents (14\% of 2020) who reported no alcohol purchasing were then excluded from the analyses (number of alcohol purchasers=1730) (Note: That these respondents reported no alcohol purchasing does not necessarily mean they are alcohol abstainers). Our initial analyse found that $85 \%$ of alcohol purchasing in Australia was off-premise, which is roughly in line with industry data on sales (78\%) [38].

\section{Statistical analysis}

In this study, the average number of ASDs purchased, the average total amount spent on alcohol and the average price per ASD among different beverages at different types of off-licence premises were calculated and analysed across demographic sub-groups (gender, age, education, income and geographical location) in the last 12 months. Most analyses were conducted by cross-tabulation analysis and graphical presentation, with $t$-statistics and one-way analysis of variance employed to test for differences in the average number of ASDs purchased and average price paid per ASD between different demographic sub-groups. 
The household income of respondents was divided into three fairly even groups -- low (annual income <AUD \$61K per year), middle (\$61K-\$114K) and high (>\$14K). Respondents were divided into equal-sized quintiles on the total volume of alcohol they purchased from off-licence premises in the last 12 months to explore differences in purchasing behaviour between different levels of alcohol purchasing, age and income groups. In all our analyses, the survey sample was weighted on the basis of the Australian Bureau of Statistics 2011 Census [39]. All data analyses were conducted in Stata Version 12.1 [40].

\section{Results}

The weighted sample proportion and the weighted average number of standard drinks purchased over 12 months at off-licence premises and price per standard drink, by different demographic factors are shown in Table 1. Male alcohol purchasers purchased nearly twice as much alcohol (1479 standard drinks) from off-licence premises as females (871 standard drinks) in the last 12 months. The amount of alcohol purchasing varied between different age groups $(F-(5)=2.85, P=0.014)$. Respondents aged 35-44 years old purchased the most alcohol (1640 ASD) in the last 12 months. There were significant differences $(F-(2)=5.28, P=0.005)$ in the amount purchased and the price per standard drink between income groups. The low income group purchased less alcohol than the high income group, and there was a trend towards an increasing price per drink paid as income rose. The highly educated group purchased more expensive alcohol ( $\$ 2.13$ per standard drink) than those with lower levels of education (for those with no more than high school education) $(F-(4)=3.46, P=0.007)$. However, alcohol purchasers with TAFE and diploma (possibly labour workers and miners) purchased more alcohol than other education levels. These findings are consistent with analyses of the National Drug Strategy Household Survey, which show that different measures of socio-economic status have different relationships with alcohol consumption [41]. 
<Insert Table 1 about here>

Table 2 presents the distribution of alcohol purchasing and the beverage-specific price per standard drink from different types of off-licence premises in the last 12 months. More than half of the total amount of alcohol (54\%) was purchased from liquor barns in Australia, with bottle shops (31\%) the second most common outlet. About five percent of alcohol was purchased direct from wineries, while $4 \%$ was sold via the phone, mail or internet. Cask wine was the cheapest type of alcohol (averaging $\$ 0.65$ per standard drink) available at off-licence premises in Australia and was significantly cheaper than the other beverage types. RTDs (Ready-to-drink premixed spirits drinks; $\$ 3.11$ per standard drink) were significantly more expensive per unit of alcohol than regular strength beer, cider, cask wine and bottled wine at off-licence premises.

\section{<Insert Table 2 about here>}

The average number of standard drinks purchased and percentage of alcohol purchased below $\mathrm{A} \$ 1$ from off-licence premises across different quintiles of purchasing and age groups are shown in Figure 1, indicating that the older age group purchased a higher proportion of their total alcohol at a price per drink cheaper than $\$ 1$, compared with middle and younger age groups, across all alcohol purchasing quintiles. In the highest quintile of purchasing, the 16-34 year age group purchased significantly more alcohol than their counterparts in the 55+ age group (about 6000 ASDs per year or 16 ASDs per day), but only $8 \%$ of their total ASDs were purchased at below \$1 per drink, significantly less than the $15 \%$ and $48 \%$ in the $35-44$ and 55 and above age groups respectively.

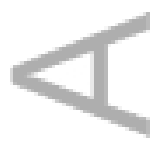

<Insert Figure 1 about here> 
Figure 2 shows the weighted average amount of standard drinks purchased and percentage of alcohol purchased below $\$ 1$ per ASD from off-licence premises across different purchasing quintiles and income groups. The lower income group purchased a higher proportion of their total alcohol than the middle and higher income groups for less than $\$ 1$ per ASD in nearly all purchasing quintiles, except for the second purchasing quintile. In the highest alcohol purchasing quintile group, lower income respondents purchased the highest average amount of standard drinks in last 12 months, with about $35 \%$ purchased below $\$ 1$ per ASD. In contrast, about $16 \%$ and $15 \%$ of total alcohol purchased from off-licence premises was below $\$ 1$ per ASD in middle and higher income groups respectively.

\section{$<$ Insert Figure 2 about here>}

\section{Discussion}

The study has presented a quantitative analysis of alcohol purchasing behaviour at different types of off-licence premises in Australia. The data on beverage-specific purchasing prices at off-licence premises show that prices varied across different types of off-licence premises. On average, liquor barns sold cheaper alcohol than other types of off-licence premises, except for purchase made via phone, internet and mail. Furthermore, liquor barns (e.g. Dan Murphy, First Choice Liquor, Liquorland) were the most popular type of packaged liquor outlet in Australia, followed by bottle shops. Regular beer, cider, RTDs and spirits sold at liquor barns were more popular for young Australians (16-34 years), while the cheap cask wine supplied by liquor barns was more popular for

older Australians (year 55+) (see Figures A.1 and A.2 in Appendix). These results may suggest that, in present market conditions, policies that control alcohol supply (i.e. alcohol sales and liquor licences) of liquor barns may achieve greater effects on reducing alcohol purchasing and greater preventive effects on alcohol-related harms than focussing on other types of off-licence premises. 
Understanding what proportion of total alcohol is purchased at a cheap price among different demographic groups is important for price policy formulation. Compared to older age groups, young people are more likely to drink heavily and experience more acute alcohol-related harms [42-44]. Previous studies suggested that raising alcohol excise tax rates or increasing alcohol prices is considered as one of the most effective ways to reduce alcohol-related harms in young people [45]. However, the survey data reveal that the younger age group purchased proportionally more spirits, RTDs and cider than older age groups; these types of beverage were generally more expensive (price per ASD) than bottle and cask wine, which were more popular in older age groups (shown in Figure A.1 in Appendix). In contrast, older heavy alcohol purchasers are likely to be the most affected by the introduction of a unit price of $\$ 1$ or by raising alcohol taxes (particularly given the high proportion of cask wine in this group's purchasing). This finding suggests that policies that increase alcohol price or tax, or introduce a minimum unit price at $\$ 1$ per standard drink, may achieve less reduction of offlicence premise purchasing among young Australian adults than among middle and older age groups. This finding is in line with a study from the UK that also suggested that a price policy introducing a minimum unit price would be less effective for a younger age group, they found young drinkers consume more of their alcohol in on-licence premises and generally pay on average a higher price for a standard drink than middle and older age drinkers [46]. With respect to public health priorities, it should be noted that, while public attention to alcohol problems tends to focus on youth drinking, this is presently trending downward [47], and that heavier drinking from middle age onward is a key issue in alcohol's important contribution to the burden of cirrhosis and other non-communicable diseases [48].

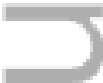

Comparing different income groups, the lower income group purchased a higher proportion of low cost alcohol across all alcohol purchasing quintiles compared with middle and high income groups, suggesting that an increase in alcohol price or tax, or introduction of a minimum unit price could have 
a greater effect in reducing alcohol purchasing among lower income groups, particularly among lower income heavy alcohol purchaser (see the fifth quintile on amount of alcohol purchasing in Figure 2). This finding is consistent with a recent study in the UK, which estimated that an introduction of a minimum unit price of $£ 0.45$ in the UK could achieve a greater reduction in alcohol consumption for low income heavy drinkers than for other population groups [27]. Najman et al. [49] found that the lower socio-economic status (SES) group reported higher liver cirrhosis mortality rate and had, over time, increased their level of harmful alcohol consumption relative to middle and higher SES groups in Australia; one possible reason is increasing affordability of alcohol over time [19]. More generally, for a given amount of alcohol consumption, lower SES groups may experience disproportionately higher level of alcohol-attributable harm [50]. Therefore, an alcohol price policy involving an increase in alcohol price or tax, or an introduction of a minimum unit price, is likely to achieve more substantial reductions in alcohol-related harms for those who purchase large amounts of alcohol in low SES than in other SES groups.

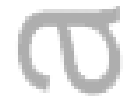

A clear implication of our analysis is that the heaviest drinking quintile purchased a higher proportion of low cost alcohol compared with other quintiles. For this group, a 15\% reduction in drinking would amount to a reduction of two drinks per day. As our analysis focused on alcohol purchasers only, and those who had no alcohol purchasing in the last 6 months were excluded. If we included those who had zero alcohol purchasing, the average purchasing amount is 866 ASDs per year, which equals to 10.3L pure alcohol per capita in 12 months, and this figure is very close to the official alcohol consumption data in 2013 from Australian Bureau of Statistics. Furthermore, this method of asking about consumption accounts for a higher proportion of sales (93\%), suggesting it is a more accurate approach than those commonly used in other surveys, that only account for 50-60\% of sales [51]. 
It worth noting that the response rates in the ACAP study is lower than in surveys in previous decades, although it is consistent with other recent Australian based RRD household surveys, such as the 2007 National Drug Strategy Household Survey (39.3\%) [52] and the Alcohol's Harm to Others Survey $2008(35.2 \%)$ [53]. The findings presented here should be treated cautiously, because since the 6 months covered by the survey included Christmas and the festival period, doubling of 6-month data to calculate annual rates may mean our results could be overestimated. Quality of memory and recall bias also could affect our estimation. The sampling frame is limited to respondents who have access to either a landline telephone or a mobile phone, and who speak English well enough to conduct a phone interview. These limitations of our scope may mean that the results are not entirely representative of the population, but given the overall accuracy of the International Alcohol Control purchasing data, any effects are likely to be small. Furthermore, this study focused only on the analyses of amounts and prices of beverage purchased across different types of off-licence premises, which does not include all consumptions, though it includes a preponderance of it. Some of the estimates presented have large confidence intervals, due to both the substantial variability in respondents' consumption and purchasing patterns and the relatively small samples among some sub-groups examined (e.g. liqueur purchases from bottle shops). Future research would benefit from larger survey samples to provide more precise estimates of uncommon drinking and purchasing behaviours.

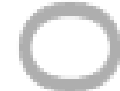

\section{Acknowledgements}

The data used in this paper are from the Australian arm of the International Alcohol Control Study, led by Professor Sally Casswell. The International Alcohol Control core survey questionnaire was largely developed by researchers at SHORE and Whariki Research Centre, College of Health, Massey University, New Zealand, with funding from the Health Promotion Agency, New Zealand. Further development involved collaboration between UK, Thai, Korean and New Zealand researchers. The 
funding source for the data set used in this article is the Australian National Preventive Health Agency (ANPHA; grant 157ROO2011). The contents of this paper are solely the responsibility of the authors and do not reflect the views of ANPHA. HJ and SC's time on this study was funded by the Foundation for Alcohol Research and Education, an independent, charitable organisation working to prevent the harmful use of alcohol in Australia: www.fare.org.au, and RR's by the Victorian Department of Health and Human Services. ML is the recipient of a National Health and Medical Research Council Early Career Fellowship.

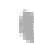
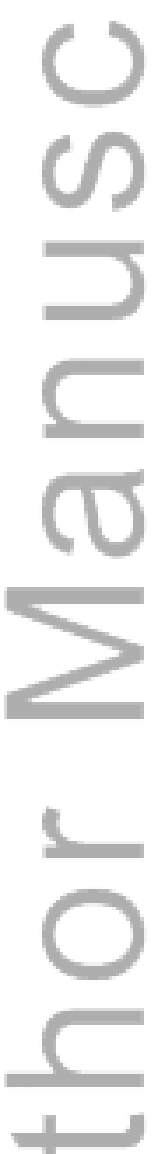

(n)

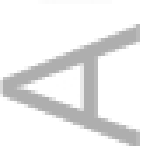

This article is protected by copyright. All rights reserved. 


\section{References}

1. Casswell S, Thamarangsi T. Alcohol and Global Health 3: Reducing harm from alcohol: call to action. Lancet 2009;373:2247-57.

2. Anderson P, Chisholm D, Fuhr DC. Effectiveness and cost-effectiveness of policies and programmes to reduce the harm caused by alcohol. Lancet 2009;373:2234-46.

3. National Competition Council, Assessment of governments' progress in implementing $=$ the National Competition Policy and related reforms, National Competition Council 1 Melbourne; 2002.

4. Room R. The dialectic of drinking in Australian life: from the Rum Corps to the wine column. Drug Alcohol Rev 1988;7:413-37.

5. Brady M. On- and off-premise drinking choices among Indigenous Australians: The influence of socio-spatial factors. Drug Alcohol Rev 2010;29:446-51.

6. Euromonitor International, Alcohol Drinks in Australia, Euromonitor London; 2012.

7. Davies JD, Bromley EE, Dickie VO, Victoria, Board of Inqury into the Operation of the Liquor Control Act 1968. Melbourne: F. D. Atkinson, Government Printer, 1978.

8. Lewis MJ, A rum state: Alcohol and state policy in Australia, 1788-1988 Canberra AGPS Press, 1992.

9. Jones E. Liquor retailing and the Woolworths/Coles juggernaut. Journal of Australian Political Economy 2005; 55: 23-47.

10. IBISWorld, Liquor retailing in Australia: Market research report, Melbourne; 2014.

11. Kypri K, Bell ML, Hay GC, Baxter J. Alcohol outlet density and university student drinking: a national study. Addiction 2008;103:1131-8.

12. Connor J, Kypri K, Bell ML, Cousins K. Alcohol outlet density, levels of drinking and alcohol-related harm in New Zealand: a national study. J Epidemiol Community Health 2011;65:841-6. 
13. Gilmore W, Liang W, Catalano P, et al., Off-site outlets and alcohol-related harm, the National Drug Law Enforcement Research Fund Canberra; 2015.

14. Treno AJ, Johnson FW, Remer LG, Gruenewald PJ. The impact of outlet densities on alcohol-related crashes: A spatial panel approach. Accid Anal Prev 2007;39:894-901.

15. Livingston M. A longitudinal analysis of alcohol outlet density and domestic violence. Addiction 2011;106:919-25.

16. $=$ Chikritzhs T, Catalano P, Pascal R, Henrickson N, Predicting alcohol-related harms from licensed outlet density: A feasibility study. Monograph, National Drug Law Enforcement Research Fund Hobart: Australia; 2007.

17. Liang W, Chikritzhs T. Revealing the link between licensed outlets and violence: Counting venues versus measuring alcohol availability. Drug Alcohol Rev 2011;30:52435.

18.

DiLoreto JT, Siegel M, Hinchey D, et al. Assessment of the Average Price and Ethanol Content of Alcoholic Beverages by Brand-United States, 2011. Alcohol Clin Exp Res 2012;36:1288-97.

19. Jiang H, Livingston M. The dynamic effects of changes in prices and affordability on alcohol consumption: an impulse response analysis. Alcohol Alcohol 2015;50:631-8.

20. Wagenaar AC, Salois MJ, Komro KA. Effects of beverage alcohol price and tax levels on drinking: a meta-analysis of 1003 estimates from 112 studies. Addiction 2009;104:17990.

21. Stockwell T, Auld MC, Zhao J, Martin G. Does minimum pricing reduce alcohol consumption? The experience of a Canadian province. Addiction 2012;107:912-20.

22. Stockwell T, Zhao J, Giesbrecht N, et al. The Raising of Minimum Alcohol Prices in Saskatchewan, Canada: Impacts on Consumption and Implications for Public Health. Am J Public Health 2012;102:e103-e110. 
23. Chalmers J, Carragher N, Davoren S, O'Brien P. Real or perceived impediments to minimum pricing of alcohol in Australia: Public opinion, the industry and the law. International Journal of Drug Policy 2013;24:517-23.

24. Meier P, Purshouse R, Brennan A. Policy options for alcohol price regulation: the - importance of modelling population heterogeneity. Addiction 2010;105:383-93.

25. Sharma A, Vandenberg B, Hollingsworth B. Minimum pricing of alcohol versus = volumetric taxation: Which policy will reduce heavy consumption without adversely affecting light and moderate consumers? PLoS ONE 2014;9:1-13.

26. Doran CM, Byrnes JM, Cobiac LJ, Vandenberg B, Vos T. Estimated impacts of alternative Australian alcohol taxation structures on consumption, public health and government revenues. Med J Aust 2013;199:619-22.

27. Holmes J, Meng Y, Meier PS, et al. Effects of minimum unit pricing for alcohol on different income and socioeconomic groups: a modelling study. Lancet 2014;383:165564.

28. Ludbrook A, Petrie D, McKenzie L, Farrar S. Tackling alcohol misuse. Appl Health Econ Health Policy 2012; 10: 51-63.

29. National Preventative Health Taskforce, Australia: Healthiest Country by 2020, Commonwealth of Australia Canberra; 2008.

30. Brennan A, Purshouse R, Taylor K, et al., Independent review of the effects of alcohol pricing and promotion: part B. Modelling the Potential Impact of Pricing and Promotion I Policies for Alcohol in England: Results from the Sheffield Alcohol Policy Model, University of Sheffield Sheffield 2008.

31. Livingston M. To reduce alcohol-related harm we need to look beyond pubs and nightclubs. Drug Alcohol Rev 2013; 32: 113-114. 

to intentional and unintentional injuries. Addiction 2015: n/a-n/a.

33. ANPHA, Exploring the public interest case for minimum (floor) price for alcohol, Australian National Preventive Health Agency Canberra; 2013.

34. Jiang H, Callinan S, Room R, Alcohol Consumption and Purchasing (ACAP) Study: Survey approach, data collection procedures and measurement of the first wave of the $=$ Australian arm of the International Alcohol Control Study, Centre for Alcohol Policy Research Melbourne; 2014.

35.

Fong GT, Cummings KM, Borland R, et al. The conceptual framework of the International Tobacco Control (ITC) Policy Evaluation Project. Tob Control 2006; 15: iii3-iii11.

36. Livingston M, Dietze P, Ferris J, et al. Surveying alcohol and other drug use through telephone sampling: a comparison of landline and mobile phone samples. BMC Med Res Methodol 2013;13:41.

37. Wyllie A, Holibar G, Jakob-Hoff M, Casswell S. A qualitative investigation of responses to the introduction of wine in New Zealand grocery outlets. Contemporary Drug Problems 1993;20:33-49.

38. Euromonitor International, Alcohol Drinks in Australia, Euromonitor London; 2015.

39. ABS, The Census of Population and Housing. Canberra: Australian Bureau of Statistics, 2011.

40. StataCorp. Stata Statistical Software: Release 12. StataCorp LP: College Station, Texas, 2011.

41. Livingston M. Socio-economic status and alcohol consumption in Australia, in the Australasian Professional Society on Alcohol and Drugs Conference. Adelaide, Australia, 2014. 
42. Kuntsche E, Knibbe R, Gmel G, Engels R. Why do young people drink? A review of drinking motives. Clin Psychol Rev 2005;25:841-61.

43. Wells S, Graham K, Speechley M, J. Koval J. Drinking patterns, drinking contexts and alcohol-related aggression among late adolescent and young adult drinkers. Addiction 2005;100:933-44.

44. Chikritzhs T, Catalano P, Stockwell P, et al., Australian Alcohol Indicators, 1990-2001:

$=$ Patterns of alcohol use and related harms for Australian states and territories., National Drug Research Institute Perth; 2003.

45. Chikritzhs T, Dietze P, Allsop S, et al. The "alcopops" tax : Heading in the right direction. Med J Aust 2009;190:294-5.

46. Purshouse RC, Meier PS, Brennan A, Taylor KB, Rafia R. Estimated effect of alcohol pricing policies on health and health economic outcomes in England: an epidemiological model. Lancet 2010;375:1355-64.

47. Livingston M. Trends in non-drinking among Australian adolescents. Addiction 2014;109:922-9.

48. Rehm J, Samokhvalov AV, Shield KD. Global burden of alcoholic liver diseases. J Hepatol 2013;59:160-8.

49. Najman JM, Williams GM, Room R. Increasing socioeconomic inequalities in male cirrhosis of the liver mortality: Australia 1981 - 2002. Drug Alcohol Rev 2007;26:273-8.

50. Schmidt L, Mäkelä P, Rehm J, Room R. Alcohol: equity and social determinants, in E Equity, Social Determinants and Public Health Programmes, E Blas, A Sivasankara Kurup, Editors. World Health Organisation: Geneva. p. 11-29 2010.

51. Livingston M, Callinan S. Underreporting in alcohol surveys: whose drinking is underestimated? J Stud Alcohol Drugs 2015;76:158-67. 
52. Australian Institute of Health and Welfare, National drug strategy household survey 2007: First results. Drug statistics series number 20. Cat. no. PHE 98, AIHW Canberra; 2008.

53. Wilkinson C, Laslett, A-M., Ferris J, et al., The range and magnitude of alcohol's harm It to others: Study design, data collection procedures and measurement, AER Centre for Alcohol Policy Research, Turning Point Alcohol \& Drug Centre Fitzroy; 2009.

(

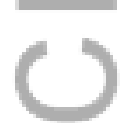

( )

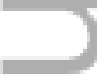

C
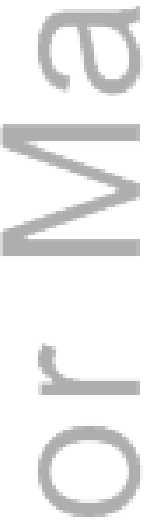

$C$

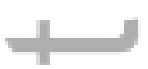

$+2$

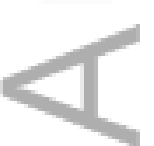

This article is protected by copyright. All rights reserved. 
Table 1. Weighted average number of standard drinks purchased and average spending on alcohol at off-licence premises in Australia by different demographic factors in last 12 months

\begin{tabular}{|c|c|c|c|c|}
\hline & $\mathrm{N}$ & $\begin{array}{l}\text { Weighted } \\
\text { percentage }\end{array}$ & $\begin{array}{l}\text { Average number of } \\
\text { standard drinks purchased } \\
{[95 \% \text { CIs] }}\end{array}$ & $\begin{array}{l}\text { Average price }(\$) \\
\text { per standard drink } \\
\text { [95\% CIs] }\end{array}$ \\
\hline \multicolumn{5}{|l|}{ Sex*** } \\
\hline Male & 1025 & $51.5 \%$ & 1479 [1056-1902] & $1.81[1.67-1.95]$ \\
\hline Female & 705 & $48.5 \%$ & 871 [739-1004] & 1.84 [1.73-1.95] \\
\hline \multicolumn{5}{|l|}{ Age* $^{*}$} \\
\hline $16-24$ & 286 & $14.1 \%$ & 1127 [794-1459] & $1.96[1.70-2.22]$ \\
\hline $25-34$ & 290 & $18.6 \%$ & $1196[855-1538]$ & $1.97[1.81-2.12]$ \\
\hline $35-44$ & 318 & $21.7 \%$ & 1640 [699-2581] & $1.79[1.56-2.02]$ \\
\hline $45-54$ & 332 & $16.6 \%$ & $1022[820-1225]$ & $1.87[1.66-2.07]$ \\
\hline $55-64$ & 289 & $15.6 \%$ & $1059[818-1300]$ & $1.76[1.54-1.97]$ \\
\hline & 215 & $13.5 \%$ & $837[665-1010]$ & $1.57[1.33-1.82]$ \\
\hline \multicolumn{5}{|l|}{ Income (223 missing) $)^{* *}$ \# } \\
\hline Low $(<\$ 61 \mathrm{~K})$ & 429 & $27.9 \%$ & 942 [780-1104] & $1.70[1.56-1.83]$ \\
\hline Middle $(\$ 61 \mathrm{~K}-\$ 114 \mathrm{~K})$ & 572 & $38.4 \%$ & 1380 [762-1998] & $1.83[1.67-1.97]$ \\
\hline $\operatorname{High}(>\$ 114 \mathrm{~K})$ & 569 & $33.8 \%$ & 1257 [1054-1459] & $1.97[1.77-2.17]$ \\
\hline \multicolumn{5}{|l|}{ Education (19 missing)**\# } \\
\hline High school and lower & 481 & $24.5 \%$ & 1124 [941.5-1307] & $1.71[1.59-1.82]$ \\
\hline Trade/non-trade certificate & 519 & $27.4 \%$ & 1268 [1029-1508] & $1.82[1.59-2.05]$ \\
\hline TAFE and diploma etc. & 214 & $12.8 \%$ & 1818 [257-3381] & $1.68[1.49-1.81]$ \\
\hline Bachelor degree & 319 & $20.9 \%$ & 894 [682-1106] & $1.89[1.71-2.06]$ \\
\hline Master degree or higher & 183 & $14.4 \%$ & 1009 [619-1398] & $2.13[1.83-2.42]$ \\
\hline \multicolumn{5}{|l|}{ Location } \\
\hline Capital cities & 1146 & $66.0 \%$ & 1207 [878-1537] & $1.88[1.75-2.00]$ \\
\hline Balance of states & 584 & $34.0 \%$ & 1138 [941-1337] & $1.74[1.61-1.86]$ \\
\hline
\end{tabular}

Note: $* P<0.05$, $* * P<0.01$ and ${ }^{* * *} P<0.001 ; t$-statistics and one-way ANOVA analysis were conducted to test the difference of average numbers of standard drink purchased by different categorical groups of demographic factors.

${ }^{\#} P<0.05 ; t$-statistics and one-way ANOVA analysis were conducted to test the difference of average price per standard drink paid by different categorical groups of demographic factors.

ANOVA, analysis of variance; CI, confidence interval. 
Table 2. The distribution of alcohol purchasing and average beverage-specific price per standard drink from different off-licence premises in the last 12 months

\begin{tabular}{|c|c|c|c|c|c|c|c|}
\hline$= \pm$ & $\begin{array}{l}\text { Liquor barn }[95 \% \\
\text { CIs] }\end{array}$ & $\begin{array}{l}\text { Convenience } \\
\text { stores [95\% CIs] }\end{array}$ & $\begin{array}{l}\text { Bottle shops [95\% } \\
\text { CIs] }\end{array}$ & $\begin{array}{l}\text { Grocery stores } \\
{[95 \% \text { CIs] }}\end{array}$ & $\begin{array}{l}\text { Winery }[95 \% \\
\text { CIs] }\end{array}$ & $\begin{array}{l}\text { Phone, email, } \\
\text { online [95\% CIs] }\end{array}$ & Total $[95 \%$ CIs] \\
\hline $\begin{array}{l}\text { Percentage of the } \\
\text { market (\% across) }\end{array}$ & 53.68 [49.96-57.60] & $3.14[2.93-3.37]$ & 30.94 [24.74-37.27] & $3.40[1.76-5.06]$ & 4.69 [3.81-5.59] & 3.95 [3.72-4.19] & $100^{a}$ \\
\hline $\begin{array}{l}\text { Mean price per } \\
\text { standard drink }(\$)\end{array}$ & & & & & & & \\
\hline Regular beer & $1.53[1.46-1.60]$ & 1.66 [1.49-1.83] & $1.68[1.59-1.76]$ & $1.73[1.58-1.88]$ & - & - & 1.57 [1.51-1.63] \\
\hline Mid-strength beer & $2.13[1.97-2.28]$ & 1.80 [1.63-1.98] & $2.31[2.03-2.58]$ & - & - & - & $2.31[2.01-2.62]$ \\
\hline Cider & 2.04 [1.73-2.35] & - & $2.32[2.00-2.63]$ & - & - & - & $2.16[1.90-2.43]$ \\
\hline Cask wine & $0.55[0.41-0.69]$ & - & $0.73[0.49-0.98]$ & - & - & - & 0.65 [0.47-0.83] \\
\hline Bottle wine & 1.83 [1.72-1.94] & $1.75[1.45-2.06]$ & 1.84 [1.74-1.95] & 1.56 [1.15-1.97] & $2.21[1.98-2.44]$ & $1.68[1.46-1.91]$ & $1.96[1.79-2.13]$ \\
\hline RTDs & $2.92[2.54-3.31]$ & 3.05 [2.61-3.49] & $3.31[2.91-3.72]$ & $3.51[2.45-4.56]$ & - & - & $3.11[2.46-3.12]$ \\
\hline Liqueurs & $2.38[1.88-2.88]$ & - & 2.24 [1.55-2.93] & - & - & - & 2.28 [1.90-2.66] \\
\hline Fortified wine & $3.70[1.33-6.08]$ & - & - & - & - & - & 3.11 [1.32-4.89] \\
\hline Spirits & $1.65[1.53-1.77]$ & 1.48 [1.28-1.69] & 1.69 [1.49-1.89] & 1.65 [1.49-1.80] & - & - & 1.67 [1.52-1.83] \\
\hline Total & 1.79 [1.70-1.89] & 1.85 [1.66-2.03] & 1.84 [1.76-1.92] & $2.11[1.61-2.60]$ & $2.23[2.00-2.46]$ & 1.64 [1.45-1.83] & 1.83 [1.74-1.92] \\
\hline
\end{tabular}

Note: "-"denotes that these results were excluded in our analysis due to the small number of observations (N <15). ${ }^{a} 0.2 \%$ of alcohol products were purchased from other types of off-licence premises in Australia.

CI, confidence interval; RTD, ready-to-drink premixed spirits drink.

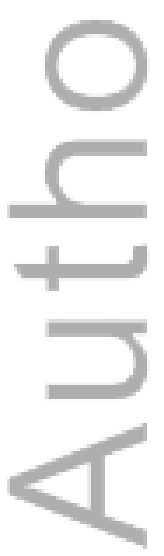




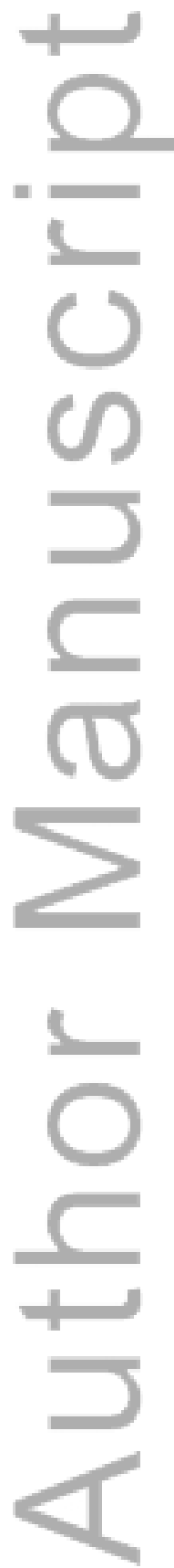

This article is protected by copyright. All rights reserved. 


\section{Appendix}

\section{The Alcohol Consumption and Purchasing Study}

The Alcohol Consumption and Purchasing study is the Australian arm of the International Alcohol Control study, initiated by Casswell et al. [1]. The Australian survey instrument is adapted from the New Zealand survey, with a few changes to fit with Australian drinking standards [2]. The International Alcohol Control study was developed on the model of the International Tobacco Control study [3] with a main goal of providing snapshots over time of alcohol consumption and purchasing across a range of countries in order to ascertain the effects of policy changes.

\section{Sampling and survey weighting}

The initial call was made to each number in the sample to recruit participants to the survey. Once a telephone or mobile number was identified as a residential number (not an answering machine, business line, fax/modem or so on), at least 10 calls were made at different times of the day and days of the week in order to attempt to reach the household. In households with multiple eligible respondents, the "most recent birthday" method of selection was used. Potential participants in the landline or mobile telephone sample were asked how often they consumed five or more standard drinks in a session. Those who stated that they did this monthly or more were asked to participate; only one-third of those that did not fit this criterion were asked to participate in the study. This was so we had sufficient power for analyses focussed on heavier drinkers (heavy and non-heavy drinkers in our survey were $67 \%$ and $33 \%$ respectively) while still allowing for survey weights to provide enough correction for a representative sample based on the distribution by drinker status in the 2010 National Drug Strategy Household Survey.

A two-stage, four-step weighting methodology was used in the survey. The first weighting stage, preweights, was done in two steps, firstly for those reached by landline to apply a weight which adjusted for the number of in-scope sample members (age 16 and over) within the household based on their date of birth. Secondly, a pre-weight is applied to correct for the overlapping of selection for persons with both a mobile phone and a fixed-line [4]. This was done to avoid disproportionate representation of those with multiple phone numbers when the mobile and landline samples were combined.

The second weighting stage, post-weights, was also done in two steps. Appropriate post-weights were used to adjust the number of heavy and non-heavy drinkers in our sample (67\% and 33\% respectively) based on the distribution by drinker status in the 2010 National Drug Strategy Household Survey (30\% and 70\% respectively) [5], as the heavy drinkers in our sample were oversampled. Despite the random sampling design, the sample demonstrated same deviation from the Australian population in relation to age and gender distribution. Hence the sample was further post-weighted by age, sex and 
geographic location proportions on the basis of the Australian Bureau of Statistics 2011 Census [6]. Full detailed information about survey sampling, weighting, and questionnaire design was elaborated in the survey technical report [2].

\section{Alcohol purchasing questions}

In the survey, the participants were asked:

- Have you purchased alcohol from ... in the last 6 months? (specifying one or more places including, a liquor barn* or a similar store, a convenience store, a bottle shop*, a small grocery store, direct from winery, phone/mail/online, and other off-licence premises);

- What types of alcohol do you usually buy from ... [nominated off-licence premises]? (including regular beer, mid-strength or light beer, cider, cask wine, bottle wine, RTDs [ready to drink beverages, premixed drinks usually with a spirits base], liqueurs, fortified wine/sherry/port/vermouth, and spirits);

- How often did you purchase [it]? (e.g. 1-2 days a week);

- How much did you usually buy from ... [nominated off-licence premises]? (e.g. 6 cans of beer, 2 bottles of spirits or 2 litres of cask wine, etc.); and

- What did you pay for ... that you purchased from ... [nominated off-licence premises]? (e.g. 30 dollars for a bottle of wine, 35 dollars for six pack of small bottles of regular beer).

*Note: As well as being the name of a particular store chain, "liquor barn" has become a general term in Australia for a large retail shop that primarily sells pre-packaged alcoholic beverages, including such chains as Dan Murphy's and First Choice Liquor, etc. A bottle shop is a small shop primarily selling alcohol, and also refers to a part of a hotel where alcohol is sold in unopened containers for consumption elsewhere.

\section{Additional figures and tables in results}

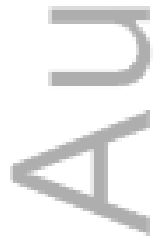




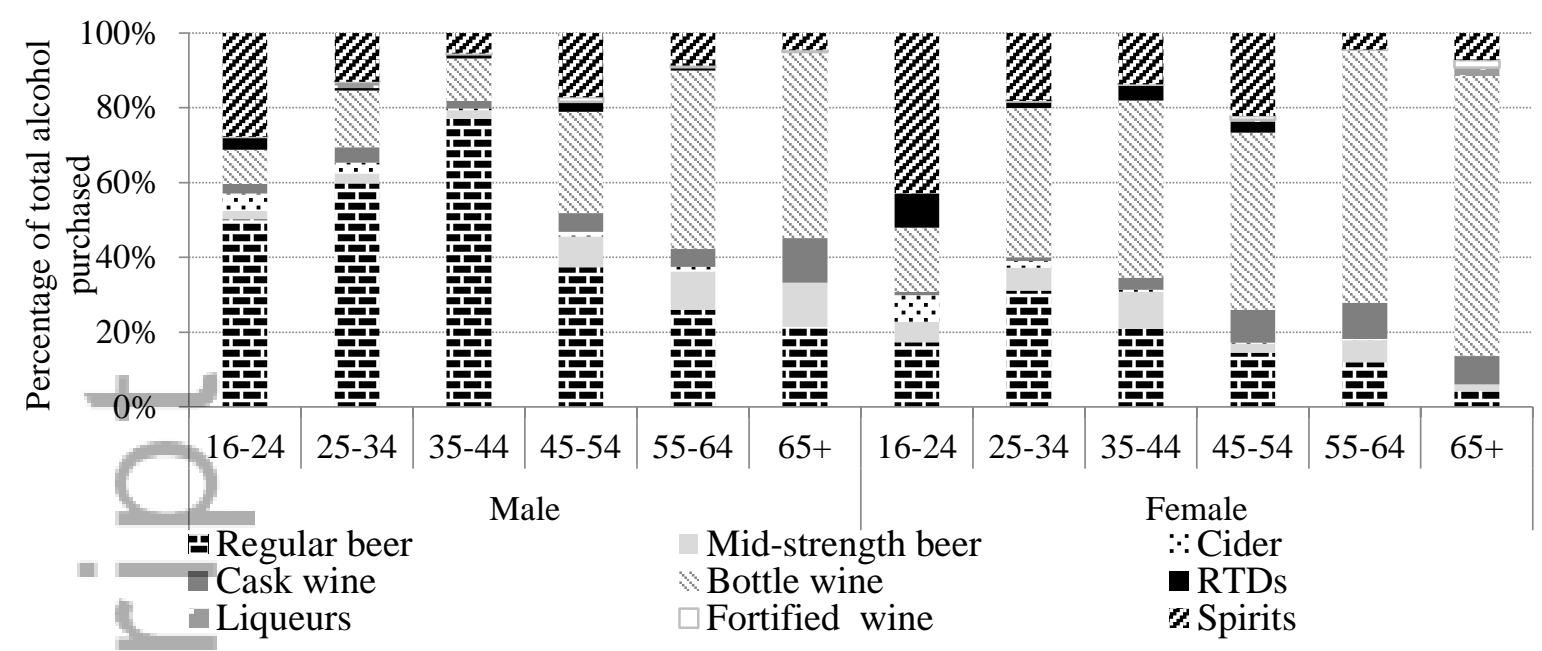

Figure A.1 Weighted proportion of standard drinks among different types of beverages purchased in the last 12 months across different sex and age groups

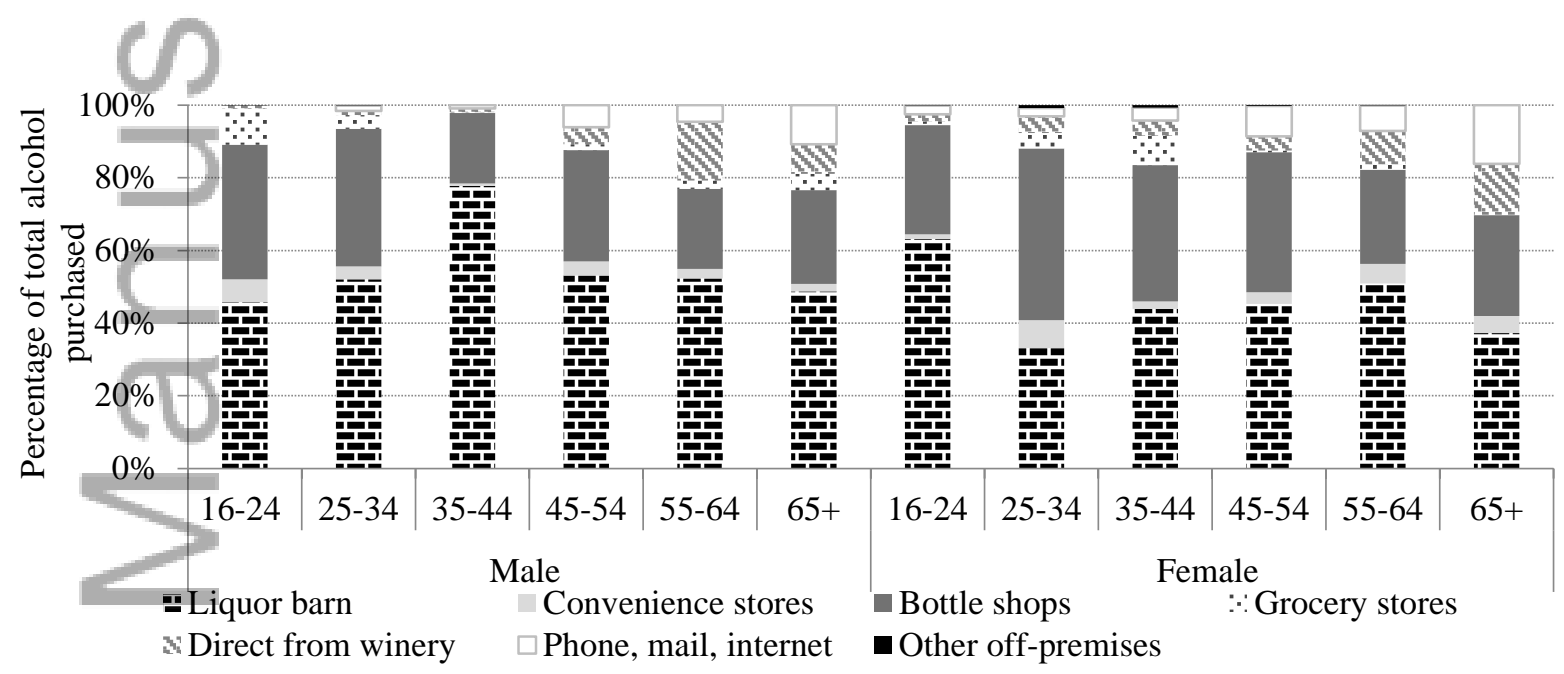

Figure A.2 Weighted proportion of standard drinks purchased in the last 12 months across different sex and age groups from different off-licence premises

Table A.1 Statistics of alcohol purchasing quintiles

\begin{tabular}{lllll}
\hline Quintiles of alcohol purchasing & $\mathrm{N}$ & $\begin{array}{l}\text { Unweighted } \\
\text { mean }\end{array}$ & $\begin{array}{l}\text { Minimum } \\
\text { values }\end{array}$ & $\begin{array}{l}\text { Maximum } \\
\text { values }\end{array}$ \\
\hline Lowest quintiles & 346 & 103.7 & 10.8 & 212.4 \\
Second quintiles & 346 & 363.1 & 212.6 & 535.6 \\
Third quintiles & 358 & 801.3 & 536.0 & 1123.2 \\
Fourth quintiles & 334 & 1587.4 & 1123.2 & 2184.0 \\
Highest quintiles & 346 & 4831.2 & 2189.2 & 49494.0 \\
\hline
\end{tabular}

\section{References}


1. Casswell S, Meier P, MacKintosh AM, et al. The International Alcohol Control (IAC) Study-Evaluating the Impact of Alcohol Policies. Alcohol Clin Exp Res 2012;36:1462-7.

2. Jiang H, Callinan S, Room R, Alcohol Consumption and Purchasing (ACAP) Study: Survey approach, data collection procedures and measurement of the first wave of the Australian arm of the International Alcohol Control Study, Centre for Alcohol Policy Research Melbourne; 2014.

3. Fong GT, Cummings KM, Borland R, et al. The conceptual framework of the International Tobacco Control (ITC) Policy Evaluation Project. Tob Control 2006;15:iii3-iii11.

4. Best J. First-Stage Weights for Overlapping Dual Frame Telephone Surveys, in Presented at AAPOR's 65th Annual Conference. Chicago, IL 2010.

5. Australian Institute of Health and Welfare, 2010 National Drug Strategy Household Survey report. Drug Statistic Series, AIHW Canberra; 2011.

6. = ABS, The Census of Population and Housing. Canberra: Australian Bureau of Statistics, 2011.

A
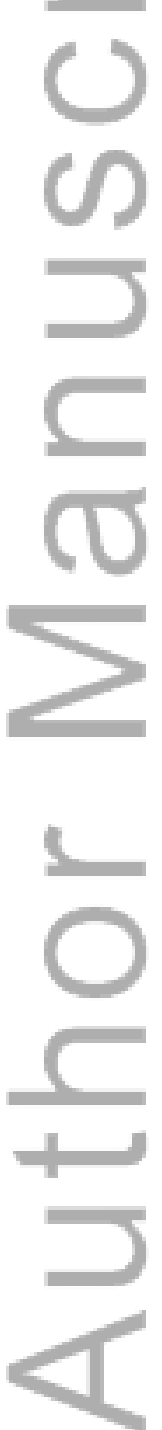

This article is protected by copyright. All rights reserved. 


\section{University Library}

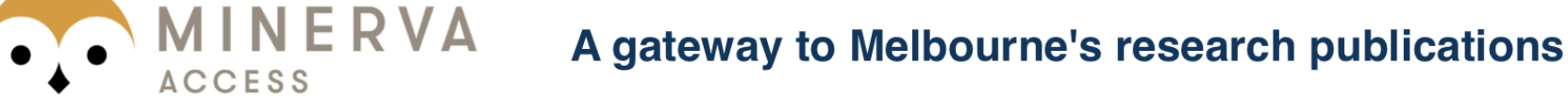

Minerva Access is the Institutional Repository of The University of Melbourne

Author/s:

Jiang, $\mathrm{H}$;Callinan, S;Livingston, M;Room, $\mathrm{R}$

Title:

Off-premise alcohol purchasing in Australia: Variations by age group, income level and annual amount purchased

Date:

2017-03-01

Citation:

Jiang, H., Callinan, S., Livingston, M. \& Room, R. (2017). Off-premise alcohol purchasing in Australia: Variations by age group, income level and annual amount purchased. DRUG AND ALCOHOL REVIEW, 36 (2), pp.210-219. https://doi.org/10.1111/dar.12402.

Persistent Link:

http://hdl.handle.net/11343/291342 